\title{
PROPAGACIÓN in vitro DEL HÍBRIDO ALMENDRO X DURAZNO H1
}

\author{
In vitro PROPAGATION OF ALMOND X PEACH HYBRID H1
}

\author{
Dulce M. Parada Ponce ${ }^{1,2}$ y Ángel Villegas Monter ${ }^{1 *}$
}

${ }^{1}$ Programa de Recursos Genéticos y Productividad - Fruticultura, Campus Montecillo, Colegio de Postgraduados. 56230, Montecillo, Texcoco, Edo. de
México. ${ }^{2}$ Dirección actual: Comisión Nacional Forestal. Av. Insurgentes No. 25, esquina con Leyes de Reforma, Col. Benito Juárez. 39010, Chilpancingo,
Gro.
*Autor para correspondencia (avillega@colpos.mx)

\section{RESUMEN}

El híbrido almendro $x$ durazno $H 1$ tiene potencial para ser utilizado como portainjerto de durazno (Prunus persica $\mathbf{L}$.) debido a que resiste sequía, suelos poco fértiles, presencia de nematodos, asfixia radical y clorosis inducida por deficiencia de Fe. Como el híbrido propagado por semilla daría segregación, se debe multiplicar vegetativamente para retener las características deseables. Una alternativa es el cultivo in vitro, con el cual se pueden obtener plantas libres de patógenos $y$ genéticamente uniformes. Para el establecimiento in vitro a quí se utilizaron ápices y fracciones de tallo más yema como explantes, obtenidos de una planta adulta, y se evaluaron tiempos de exposición a hipoclorito de sodio para la desinfestación. Se emplearon dos medios de cultivo, Woody Plant Medium (WPM) y WPM modificado (WPMm), y durante la etapa de proliferación se probaron cuatro niveles de nitrato de amonio y tres de benciladenina (BA). Para el enraizamiento se probaron cuatro niveles de auxina. El menor porcentaje de contaminación (6.6\%) se logró con ápices, pero el mayor establecimiento $(44 \%)$ in vitro ocurrió con secciones nodales del tallo en el medio WPM. En la fase de multiplicación, el mayor número de brotes (20.4) se logró en medio WPM adicionado con $2 \mathrm{mM}$ de nitrato de amonio más $2.5 \mu \mathrm{M}$ de BA. La aplicación de ácido indolbutírico promovió el enraizamiento in vitro, pues al aumentar la concentración de auxina se incrementó el número de raíces, pero disminuyó su longitud. El enraizamiento y la aclimatación se pueden realizar simultáneamente si se aplica Radix 10 $000 \AA$ a $20 \%(\mathrm{p} / \mathrm{p})$ durante el trasplante, y así se evitaría la fase de enraizamiento in vitro. El protocolo aquí empleado permitió la micropropagación del híbrido almendro $\mathrm{x}$ durazno $\mathrm{H1}$ a partir de plantas adultas desarrolladas en campo.

Palabras clave: Prunus spp., cultivo in vitro, portainjerto, híbrido durazno x almendro.

\section{SUMMARY}

The almond $\mathrm{x}$ peach hybrid $\mathrm{H} 1$ has the potential to be used as a peach (Prunus persica L.) rootstock, because it its highly resistant to drought, dry soils with low fertility, nematods, root asphyxia, and chlorosis induced by $\mathrm{Fe}$ deficiency. Since a hybrid propagated by seeds would produce segregation, for maintaining the desired plant traits the hybrid should be multiplied by vegetative methods. An alternative for commercial vegetative propagation is the in vitro culture, which can be used to obtain free pathogen plants genetically uniform. In this research shoot tips and stem nodal sections from a mature tree were used as explants for the establishment of the in vitro cultures. Exposure time to chlorine was evaluated for disinfection. Two culture media were tested: Woody Plant Medium (WPM) and WPM modified (WPMm). During the proliferation stage, four levels of ammonium nitrate and three levels of benzyl adenine were tested, and during the in vitro rooting four levels of auxin were tested. The lowest percent of contamination (6.6\%) was accomplished on apices; the best establishment in vitro (44\%) was achieved with stem nodal sections growing on the WPM medium. For the in vitro multiplication the best treatment was the WPM medium added with $2 \mathrm{mM}$ of ammonium nitrate plus $2.5 \mu \mathrm{M}$ of BA. For the in vitro rooting, indole butyric acid promoted an increase in the number of roots, but this auxin also shortened the roots. The rooting and acclimatization can be performed simultaneously with Radix $10000 \AA$ at $20 \%(\mathrm{p} / \mathrm{p})$ if it is applied during transplant. The protocol generated here allows the propagation of the hybrid almond $x$ peach $\mathrm{H1}$ of explants obtained from adult plants grown in field conditions. hybrid.

Index words: Prunus spp., in vitro culture, rootstock, almond/peach

\section{INTRODUCCIÓN}

La producción de durazno (Prunus pérsica L.) en México se ha visto afectada principalmente por nematodos, $\mathrm{y}$ por suelos pobres y alcalinos con problemas de replantación. Esto, aunado a la falta de producción en vivero de plantas de calidad sanitaria y la creciente exigencia del consumidor, ha provocado que la producción de durazno no sea comercialmente competitiva a nivel mundial a pesar de tener potencial para lograrlo (Enríquez, 2001). Además, en México los portainjertos de durazno se propagan a partir de semilla, lo cual ocasiona que la producción resulte heterogénea en la misma plantación. En Europa y Brasil el uso de híbridos de Prunus como portainjertos ha resuelto problemas de replantación, asfixia radical, nematodos (Couto et al., 2004), suelos poco fértiles, secos (Salazar y Melgarejo, 2002) y alcalinos 
(Valentini et al., 2006); y su propagación comercial se lleva a cabo por medio del cultivo in vitro (Tsipouridis y Thomidis, 2003).

Debido a que los requerimientos para micropropagar son específicos para cada genotipo, es necesario establecer protocolos para cada portainjerto (George, 1993; Hartmann et al., 2002). Así, en la etapa “0”, en la que se acondicionan las plantas madre (donadoras de explantes), los tratamientos que se utilizan dependen de las condiciones en las cuales se desarrollan las plantas; si se encuentran en campo la posibilidad de contaminación es mayor que si se mantienen en invernadero, mientras que las plántulas derivados de semilla han estado menos expuestas a los contaminantes (Villegas, 1990). Comúnmente se hacen aplicaciones de fungicidas y bactericidas sistémicos con el fin de disminuir la contaminación, aunque no siempre con buenos resultados (Rodrigues et al., 2003).

Para el establecimiento in vitro de Prunus, como explantes se han utilizado ápices (Tabachnik y Kester, 1977; Deogratias et al., 1986; Theiler- Hedtrich y Feucht, 1985) y secciones nodales de tallo (Rodrigues et al., 2003; Couto et al., 2004). La fecha de establecimiento también es determinante en la adaptación a las condiciones in vitro; así, en verano la contaminación es baja mientras que en otoño es alta (Rodrigues et al., 2003). Los porcentajes de establecimiento y brotación obtenidos en Prunus han sido variables; p. e., Rodrigues et al. (2003) reportaron $15 \%$ mientras que Da Silva et al. (2003) lograron $63 \%$. Otro factor importante es el medio de cultivo utilizado; según Pérez-Tornero y Burgos (2000), las especies de Prunus son sensibles a altas concentraciones de amonio en el medio de cultivo, mientras que para Couto et al. (2004) no existe influencia del medio.

Para la fase de multiplicación, en Prunus se han utilizado concentraciones variables de citocininas $(0$ a $17.76 \mu \mathrm{M}$ ) (Channuntapipat et al., 2003; Fotopoulos y Sotiropoulos, 2004). Comúnmente se utiliza benciladenina (BA), que Rogalski et al. (2003) reportan como la más efectiva, aunque aplicada en altas concentraciones $(17.76 \mu \mathrm{M})$ inhibe la elongación de brotes $\mathrm{y}$ promueve hiperhidratación (Tabachnik y Kester, 1977; Channuntapipat et al., 2003). De ahí surge la importancia de combinar dosis adecuadas de citocininas con dosis bajas de auxinas $(0.01 \mu \mathrm{M})$. Las tasas de multiplicación registradas en Prunus han variado tanto que se ha concluido que la respuesta depende del genotipo (Rogalski et al., 2003; Espinosa et al., 2006).

Para la multiplicación in vitro se ha utilizado el medio de cultivo de Murahige y Skoog (MS) (1962), pero con modificaciones en el contenido de nitrógeno, debido a que el nivel de amonio en el medio ha sido excesivo para el cultivo de chabacano (Prunus armeniaca) (Pérez-Tornero y Burgos, 2000). Durante el enraizamiento se han utilizado auxinas como ácido indolbutírico (AIB), ácido indolacético (AIA) y ácido naftalenacético (ANA) (Channuntapipat et al., 2003; Espinosa et al., 2006), en diversas concentraciones, pero evitando aplicar niveles mayores de $4.42 \mu \mathrm{M}$ de AIB porque afectan negativamente la formación de raíces.

La aclimatación a condiciones ex vitro ha resultado la fase más complicada debido a que en ella ocurren las mayores pérdidas (Marin, 2003); el éxito depende de los tratamientos aplicados en las etapas previas in vitro, además de la capacidad de los brotes para adaptarse a las condiciones ex vitro (Rogalski et al., 2003). Es importante considerar que la mayoría de trabajos publicados se han llevado a cabo con explantes provenientes de semilla, debido a la respuesta restringida que se obtiene con materiales adultos de Prunus. Por ello, el objetivo de este trabajo fue establecer un protocolo eficiente de propagación in vitro para plantas adultas del híbrido almendro x durazno $\mathrm{H} 1$, en cuanto a tipos de explante, épocas de establecimiento y medios de cultivo.

\section{MATERIALES Y MÉTODOS}

El híbrido $\mathrm{H} 1$ es una cruza de los cultivares 'Dulce Marrakech' x 'Flordaguard', con amplias posibilidades de ser utilizado como portainjerto de durazno en suelos pobres, alcalinos y con problemas de replantación. El híbrido $\mathrm{H} 1$ es un ejemplar único que se encuentra en el huerto experimental del Colegio de Postgraduados, en Texcoco, Edo. de México.

\section{Establecimiento in Vitro}

Para esta fase se cortaron varetas de 2 a 4 meses provenientes del árbol adulto en producción. Para su desinfestación, en el laboratorio las varetas se lavaron con agua y detergente; posteriormente se cortaron en secciones de 4 a $5 \mathrm{~cm}$, se colocaron en un frasco en donde se les aplicó $30 \mathrm{~mL}$ de jabón antibacterial y se agitaron durante $15 \mathrm{~min}$ a $250 \mathrm{rpm}$. Enseguida se enjuagaron con agua corriente y se colocaron en solución con $2 \mathrm{~g} \mathrm{~L}^{-1} \mathrm{de}$ fungicida Captán® y $2 \mathrm{~g} \mathrm{~L}^{-1}$ de bactericida Agygent plus $800 \AA$ por $15 \mathrm{~min}$, en agitación a $250 \mathrm{rpm}$. Después los explantes se enjuagaron con agua corriente y se colocaron en una solución con $3 \mathrm{~g} \mathrm{~L}^{-1}$ de Timsen®. En la campana de flujo laminar, los explantes se trataron con alcohol a $70 \%$ durante 1 min, y después las secciones nodales se mantuvieron en hipoclorito de sodio (Cloralex®) a $10 \%$ (v/v) durante 5, 10 y 15 min, mientras que los ápices 
obtenidos de las varetas sólo se trataron durante $5 \mathrm{~min}$. Por último, se dieron cuatro enjuagues con agua destilada estéril y se procedió a sembrar los ápices y secciones nodales en el medio de cultivo para inducir la brotación.

Se evaluaron dos medios de cultivo (Cuadro 1), WPM (Lloyd y McCown, 1980) y WPM modificado, debido a que el $\mathrm{CaCl}_{2}$ es considerado tóxico (Villegas et al., 1992). En todos los casos el medio fue complementado con: tiamina 0.4 , mioinositol 100, agar 6000 y sacarosa 30000 (en $\left.\mathrm{mg} \mathrm{L}^{-1}\right)$. El experimento se repitió en dos fechas ( $22 \mathrm{de}$ marzo y 25 de mayo de 2005) y para cada tratamiento se utilizaron tres repeticiones de cinco explantes cada una. Los explantes se establecieron en tubos de ensayo que contenían $10 \mathrm{~mL}$ de medio de cultivo, que se mantuvieron en cuarto de incubación con fotoperiodo de $16 \mathrm{~h}$, intensidad lumínica de $76 \mu \mathrm{mol} \mathrm{m}^{-2} \mathrm{~s}^{-1}$ y $8 \mathrm{~h}$ de oscuridad, con temperatura de $25 \pm 2{ }^{\circ} \mathrm{C}$. La evaluación de los porcentajes de contaminación, explantes vivos, muertos y brotados, se hizo a las cuatro semanas después del establecimiento.

\section{Multiplicación in vitro}

Durante esta fase se utilizaron brotes desarrollados in vitro y subcultivados seis o más veces; se evaluaron cuatro concentraciones de $\mathrm{NH}_{4} \mathrm{NO}_{3}(0.0,2.0,4.0$ y $8.0 \mathrm{mM})$ y tres de benciladenina BA $(2.5,5.0$ y $10 \mu \mathrm{M})$, para un total de 12 tratamientos. Para cada tratamiento se utilizaron cuatro frascos de vidrio con capacidad de $100 \mathrm{~mL}$ que contenían $20 \mathrm{~mL}$ del medio de cultivo WPM (Cuadro 1), con cuatro explantes cada uno. El $\mathrm{pH}$ del medio de cultivo se ajustó a 5.5 antes de adicionar el $\mathrm{NH}_{4} \mathrm{NO}_{3}$ o la BA. Después de cuatro semanas se evaluó: número, longitud y porcentaje de agua en todos los brotes de cada tratamiento. El experimento se repitió cuatro veces.

\section{Enraizamiento in Vitro}

Para esta etapa se probaron cuatro concentraciones de AIB $(0,0.1,2.1$ y $3.4 \mu \mathrm{M})$ y se utilizaron brotes de $1.5 \mathrm{a}$ $2 \mathrm{~cm}$ de longitud que provenían de siete o más subcultivos. En cada tratamiento se utilizaron cinco frascos de vidrio de $100 \mathrm{~mL}$ que contenían $20 \mathrm{~mL}$ del medio de cultivo para enraizamiento (ME) (Villegas et al., 1992; Cuadro 1), con cuatro explantes cada uno. El experimento se repitió en dos ocasiones y en ellos se evaluó número y longitud de raíces. En la primera repetición el registro de datos se hizo a la cuarta semana, y en la segunda a la tercera semana, debido a que la producción de callo se incrementó considerablemente en la cuarta semana. Las raíces largas dificultaron el trasplante a suelo. Las condiciones de incubación fueron las mismas que para el establecimiento in vitro.
Cuadro 1. Composición de los medios de cultivo Woody Plant Medium (WPM) y Woody Plant Medium modificado (WPMm) y medio para enraizamiento (ME).

\begin{tabular}{|c|c|c|c|}
\hline & $\begin{array}{c}\text { WPM } \\
\left(\mathrm{mg} \mathrm{L}^{-1}\right)\end{array}$ & $\begin{array}{l}\text { WPMm } \\
\left(\mathrm{mg} \mathrm{L}^{-1}\right)\end{array}$ & $\begin{array}{c}\mathrm{ME} \\
\left(\mathrm{mg} \mathrm{L}^{-1}\right)\end{array}$ \\
\hline \multicolumn{4}{|l|}{ Nutrimento } \\
\hline $\mathrm{NH}_{4} \mathrm{NO}_{3}$ & 400 & 400 & 960 \\
\hline $\mathrm{Mg} \mathrm{SO}_{4}$ & 370 & 370 & 370 \\
\hline $\mathrm{KH}_{2} \mathrm{PO}_{4}$ & 170 & 170 & 170 \\
\hline $\mathrm{CaCl}_{2} .2 \mathrm{H}_{2} \mathrm{O}$ & 96 & & \\
\hline $\mathrm{Ca}\left(\mathrm{NO}_{3}\right)_{2} .4 \mathrm{H}_{2} \mathrm{O}$ & 556 & 695 & 354 \\
\hline $\mathrm{K}_{2} \mathrm{SO}_{4}$ & 990 & & \\
\hline $\mathrm{KNO}_{3}$ & & & 1011 \\
\hline \multicolumn{4}{|l|}{ Quelatos } \\
\hline $\mathrm{Na}_{2}$ EDTA. $2 \mathrm{H}_{2} \mathrm{O}$ & 37.2 & 37.2 & 37.2 \\
\hline $\mathrm{FeSO}_{4} \cdot 7 \mathrm{H}_{2} \mathrm{O}$ & 27.8 & 27.8 & 27.8 \\
\hline \multicolumn{4}{|l|}{ Microelementos } \\
\hline $\mathrm{H}_{3} \mathrm{BO}_{3}$ & 6.2 & 6.2 & 6.2 \\
\hline $\mathrm{Mn} \mathrm{SO}_{4} .4 \mathrm{H}_{2} \mathrm{O}$ & 22.3 & 22.3 & 8.4 \\
\hline $\mathrm{ZnSO}_{4} .7 \mathrm{H}_{2} \mathrm{O}$ & 8.6 & 8.6 & 8.6 \\
\hline $\mathrm{Na}_{2} \mathrm{Mo} \mathrm{O}_{4} \cdot 2 \mathrm{H}_{2} \mathrm{O}$ & 0.25 & 0.25 & 0.25 \\
\hline $\mathrm{CuSO}_{4} .5 \mathrm{H}_{2} \mathrm{O}$ & 0.25 & 0.25 & 0.025 \\
\hline $\mathrm{CoCl}_{2} .6 \mathrm{H}_{2} \mathrm{O}$ & & & 0.025 \\
\hline
\end{tabular}

\section{Aclimatación}

Los explantes provenientes de la fase de enraizamiento fueron trasplantados a charolas de 70 cavidades rellenas con "peat moss" humedecido a capacidad de campo. Para eliminar por completo el medio de cultivo, los brotes fueron lavados con agua tibia, y a los que no enraizaron se les aplicó en la base Radix $10000 \circledast$ a 20 \% (p/p). Las charolas se taparon con cubiertas plásticas y se colocaron en una cámara de crecimiento con humedad relativa de $90 \%$ y $34{ }^{\circ} \mathrm{C}$ de temperatura en el sustrato. Después de tres semanas se retiró la cubierta y permanecieron ahí durante un mes más. Posteriormente se colocaron en invernadero con malla sombra de $30 \%$, y después de dos meses se evaluó el porcentaje de sobrevivencia. Las condiciones del invernadero fueron: humedad relativa promedio de $77 \%$ y temperatura promedio de $22.6{ }^{\circ} \mathrm{C}$, mínima de $15{ }^{\circ} \mathrm{C}$ y máxima de $41.5{ }^{\circ} \mathrm{C}$. El riego se hizo con agua destilada.

\section{Análisis estadístico}

En todos los experimentos el diseño experimental empleado fue completamente al azar con arreglo factorial de tratamientos. El análisis de los datos consistió de análisis de varianza y pruebas de medias de Tukey $(\alpha=$ 0.05), con excepción de la aclimatación donde se empleó coeficiente de correlación. En las variables de porcentaje se procedió a la transformación arcoseno de los valores previo al análisis respectivo, con el programa SAS, versión 9.1. 


\section{RESULTADOS Y DISCUSIÓN}

\section{Establecimiento in Vitro}

El análisis de varianza mostró efectos significativos $(\mathrm{P} \leq 0.05)$ para las interacciones tipo de explante $\mathrm{x}$ tiempo de exposición al hipoclorito de sodio, $\mathrm{y}$ tipo de explante $\mathrm{x}$ fecha de establecimiento. En el uso de ápices como explantes, la fecha de establecimiento influyó en la contaminación por hongos; así, en la fecha 1 (22 de marzo) la contaminación por hongos fue mayor $(5.5 \%)$ que en la fecha 2 (25 de mayo, $1.1 \%)$. En la contaminación por bacterias no hubo diferencias estadísticas entre fechas (Cuadro 2). Estos resultados confirman que la contaminación puede variar entre épocas del año y entre edades de las plantas madre (TheilerHedtrich y Feucht, 1985; Kamali et al., 2001). Estos porcentajes de contaminación fueron bajos al compararlos con los de otros estudios: $14.8 \%$ obtenido por Da Silva et al. (2003), $50 \%$ por Rodrigues et al. (2003) y $70 \%$ en yemas en letargo (Hammerschlag, 1982), en los cuales no se especifica el tipo de contaminante. Por tanto, el protocolo de desinfestación aquí empleado fue eficiente para plantas desarrolladas en campo.

El porcentaje de explantes que sobrevivieron y brotaron durante el establecimiento in vitro, fueron mayores en la primera fecha ( 22 de marzo) con $28.9 \%$ que en la segunda (Cuadro 2), lo que evidencia la importancia de la época de colecta de estos explantes. Kamali et al. (2001) y Hammerschlag (1982) recomiendan que la colecta se realice durante el crecimiento vegetativo activo. Con base en lo aquí observado, la colecta de explantes en plantas adultas del híbrido $\mathrm{H} 1$ que crecen en campo se debe hacer al inicio de la brotación (22 de marzo)

Cuadro 2. Efecto de la fecha de establecimiento in vitro en el comportamiento de ápices del hibrido almendro x durazno H1.

\begin{tabular}{|c|c|c|c|c|c|}
\hline \multirow[b]{2}{*}{ Fecha } & \multicolumn{2}{|c|}{ Contaminación (\%) } & \multicolumn{3}{|c|}{ Estado de los explantes (\%) } \\
\hline & Hongos & Bacterias & Vivos & Brotados & Muertos \\
\hline $22 / 03 / 05$ & $5.5 \mathrm{a}$ & $0.0 \mathrm{a}$ & 28.9 a & $28.9 \mathrm{a}$ & $65.5 \mathrm{~b}$ \\
\hline $25 / 05 / 05$ & $1.1 \mathrm{~b}$ & $2.2 \mathrm{a}$ & $14.4 \mathrm{~b}$ & $14.4 \mathrm{~b}$ & $83.3 \mathrm{a}$ \\
\hline DMS & 3.9 & 3.2 & 3.2 & 3.2 & 3.9 \\
\hline
\end{tabular}

Medias con letras iguales en la misma columna, no presentan diferencias significativas (Tukey, 0.05). DMS $=$ Diferencia mínima significativa.

Entre los dos medios de cultivo hubo diferencias $(\mathrm{P} \leq 0.05)$ en cuanto a las variables explantes vivos, brotados, muertos y contaminados por hongos y bacterias. Los mayores porcentajes de explantes que produjeron brotes $(43.4 \%)$ se obtuvieron con el medio WPM (Cuadro $3)$. Esta respuesta es superior a la reportada por Rodrigues et al. (2003), quienes obtuvieron de 18 a $40 \%$ con el hibrido almendro x durazno GF-677.

Cuadro 3. Efecto del medio de cultivo en el porcentaje de contaminación y brotación de secciones nodales del híbrido almendro $\mathrm{x}$ durazno H1, establecidos in vitro.

\begin{tabular}{lcccccc}
\hline \multirow{2}{*}{ Medio } & \multicolumn{2}{c}{ Contaminación (\%) } & & \multicolumn{3}{c}{ Estado de los explantes (\%) } \\
\cline { 2 - 3 } \cline { 5 - 7 } & \multirow{2}{*}{ Hongos } & Bacterias & & Vivos & Brotados & Muertos \\
\hline WPM & $18.5 \mathrm{a}$ & $20.4 \mathrm{a}$ & & $44.1 \mathrm{a}$ & $43.3 \mathrm{a}$ & $17.4 \mathrm{~b}$ \\
WPMm & $5.2 \mathrm{~b}$ & $4.1 \mathrm{~b}$ & & $20.4 \mathrm{~b}$ & $20.4 \mathrm{~b}$ & $70.4 \mathrm{a}$ \\
DMS & 3.9 & 3.4 & & 4.0 & 3.9 & 4.4 \\
\hline
\end{tabular}

Medias con letras iguales en la misma columna, no presentan diferencias significativas (Tukey, 0.05). DMS $=$ Diferencia mínima significativa $\mathrm{WPM}=$ Woody Plant Medium; WPMm = Woody Plant Medium, modificado.

Al analizar la efectividad de los tres tiempos de exposición de secciones nodales al hipoclorito de sodio (Cloralex®), se encontró que este factor únicamente influyó en la incidencia de hongos, y que los tiempos más efectivos fueron 10 y $15 \mathrm{~min}$, con 10 y $9.4 \%$ de contaminación. Las variables restantes (contaminación por bacterias, brotación, explantes vivos y muertos) no presentaron diferencias $(\mathrm{P}=0.37)$ entre medios de cultivo. Finalmente, al comparar el desempeño de ambos tipos de explante al ser expuestos por $5 \mathrm{~min}$ al hipoclorito de sodio, se observó que los ápices se contaminaron menos $(\mathrm{P} \leq 0.05)$ que las secciones nodales, tanto por hongos como por bacterias; esto sugiere que a menor tamaño de explante, menor contaminación. En cuanto a sobrevivencia y brotación, las secciones nodales del tallo presentaron porcentajes mayores que los ápices. Los ápices murieron en mayor proporción (74.4 \%) que las secciones nodales (Cuadro 4). Esto implica que se pueden utilizar ápices para obtener plantas con prueba negativa para algún virus de interés, o usar secciones nodales para multiplicar los explantes.

Cuadro 4. Efecto del tipo de explante (ápices y secciones nodales) en el porcentaje de contaminación $\mathrm{y}$ brotación in vitro del híbrido almendro $\mathrm{x}$ durazno $\mathrm{H} 1$.

\begin{tabular}{lcccccc}
\hline \multirow{2}{*}{ Explante } & \multicolumn{2}{c}{ Contaminación (\%) } & & \multicolumn{3}{c}{ Estado de los explantes (\%) } \\
\cline { 2 - 3 } \cline { 5 - 7 } & \multirow{2}{*}{ Hongos } & Bacterias & & Vivos & Brotados & Muertos \\
\hline Ápice & $3.3 \mathrm{~b}$ & $1.1 \mathrm{~b}$ & & $21.7 \mathrm{~b}$ & $21.7 \mathrm{~b}$ & $74.4 \mathrm{a}$ \\
S. nodal & $16.1 \mathrm{a}$ & $10.5 \mathrm{a}$ & & $33.3 \mathrm{a}$ & $33.3 \mathrm{a}$ & $40.0 \mathrm{~b}$ \\
DMS & 3.8 & 3.1 & & 3.7 & 3.7 & 4.6 \\
\hline
\end{tabular}

Medias con letras iguales en la misma columna, no presentan diferencias significativas (Tukey, 0.05). DMS $=$ Diferencia mínima significativa.

Al tomar en cuenta que la contaminación reportada en Prunus varía de $3 \%$ (Rodrigues et al., 2003) a $90 \%$ (Hammerschlag, 1982; Couto et al., 2004), se infiere que el protocolo de desinfestación empleado fue apropiado para plantas adultas del híbrido H1 desarrolladas en campo. 


\section{Multiplicación in vitro}

El análisis de varianza mostró diferencias significativas entre tratamientos para número y longitud de brotes y contenido de agua $(\mathrm{P} \leq 0.01)$ durante la etapa de proliferación. Al comparar los promedios de diversas concentraciones de $\mathrm{NH}_{4} \mathrm{NO}_{3}$ y $\mathrm{BA}$, se detectaron diferencias $(\mathrm{P} \leq 0.05)$ entre tratamientos (Cuadro 5). En el número de brotes hubo efecto significativo del nitrato de amonio, pero no de citocininas ni de la interacción nitrato $\mathrm{x}$ citocinina. El mayor número de brotes (20.4) se obtuvo en el tratamiento con $2 \mathrm{mM}$ de $\mathrm{NH}_{4} \mathrm{NO}_{3}$ y $2.5 \mu \mathrm{M}$ de BA, que fue estadísticamente igual a los tratamientos 5, 6, 9 y 12 (Cuadro 5). Puesto que los medios con $2 \mathrm{mM}$ de $\mathrm{NH}_{4} \mathrm{NO}_{3}$ obtuvieron mayor número de brotes independientemente de la concentración de BA, no se justifica el uso de medios de cultivo con altos niveles de amonio (10 a $20 \mathrm{mM}$ ) que además han resultado tóxicos para Prunus (Pérez-Tornero y Burgos, 2000). El menor número de brotes se presentó en los medios $\sin \mathrm{NH}_{4} \mathrm{NO}_{3}$, independientemente de la concentración de BA, lo que pone en evidencia la importancia de este nutrimento en la multiplicación in vitro. Al respecto, en la literatura consultada la proliferación solamente es atribuida a la concentración de citocininas (Tabachnik y Kester, 1977; Hartmann et al., 2002; Posser et al., 2001), y estos resultados demuestran que se debe considerar también la interacción entre $\mathrm{NH}_{4} \mathrm{NO}_{3}$ y BA, así como otros componentes del medio de cultivo (Villegas et al., 1992; Pérez-Tornero y Burgos, 2000).

En la longitud de brotes también hubo efecto de los tratamientos (Cuadro 5). Los de mayor longitud fueron los que crecieron con 2.5 y $5.0 \mu \mathrm{M}$ de BA, independientemente de la concentración de $\mathrm{NH}_{4} \mathrm{NO}_{3}$. Así, en el tratamiento $4\left(10 \mu \mathrm{M}\right.$ de $\mathrm{BA}+4 \mathrm{mM}$ de $\left.\mathrm{NH}_{4} \mathrm{NO}_{3}\right)$ los brotes fueron de menor tamaño y en el tratamiento 7 (2.5 $\mu \mathrm{M}$ de $\mathrm{BA}+4 \mathrm{mM}$ de $\left.\mathrm{NH}_{4} \mathrm{NO}_{3}\right)$ los de mayor tamaño (Cuadro 5). Lo anterior confirma nuevamente la importancia de la interacción $\mathrm{NH}_{4} \mathrm{NO}_{3}$ x BA durante la proliferación del híbrido H1. Dado que las concentraciones de $\mathrm{NH}_{4} \mathrm{NO}_{3}$ que generalmente se utilizan en los medios de cultivo para la micropropagación de Prunus son de 10 a 20 $\mathrm{mM}$, los resultados aquí obtenidos indican que tales concentraciones se deberían reducir, según la especie o cultivar, como también señalan Vieitez et al. (1985), Ruzic et al. (2000) y Pérez-Tornero y Burgos (2000), para lograr mayor número de brotes y, como se mostrará adelante, para reducir problemas de hiperhidratación.
Cuadro 5. Efecto de la concentración del $\mathrm{NH}_{4} \mathrm{NO}_{3}$ y $\mathrm{BA}$ en el número $\mathrm{y}$ longitud de brotes del híbrido almendro $\mathrm{x}$ durazno $\mathrm{H1}$ cultivados in vitro.

\begin{tabular}{cccccc}
\hline \multicolumn{3}{c}{ Tratamientos } & & & \multicolumn{2}{c}{ Brotes } \\
\cline { 1 - 2 } \cline { 5 - 6 } Núm. & $\begin{array}{c}\mathrm{NH}_{4} \mathrm{NO}_{3} \\
(\mathrm{mM})\end{array}$ & $\begin{array}{c}\mathrm{BA} \\
(\mu \mathrm{M})\end{array}$ & & Número & $\begin{array}{c}\text { Longitud } \\
(\mathrm{cm})\end{array}$ \\
\hline 4 & 2 & 2.5 & & $20.4 \mathrm{a}$ & $1.4 \mathrm{ab}$ \\
5 & 2 & 5.0 & & $19.6 \mathrm{ab}$ & $1.1 \mathrm{abc}$ \\
6 & 2 & 10.0 & & $14.5 \mathrm{abc}$ & $0.9 \mathrm{bc}$ \\
9 & 4 & 10.0 & & $14.4 \mathrm{abc}$ & $0.9 \mathrm{c}$ \\
12 & 8 & 10.0 & & $10.9 \mathrm{abc}$ & $0.9 \mathrm{bc}$ \\
8 & 4 & 5.0 & & $9.9 \mathrm{bc}$ & $1.2 \mathrm{abc}$ \\
7 & 4 & 2.5 & & $9.6 \mathrm{bc}$ & $1.4 \mathrm{a}$ \\
11 & 8 & 5.0 & & $9.1 \mathrm{c}$ & $1.1 \mathrm{abc}$ \\
10 & 8 & 2.5 & & $7.5 \mathrm{c}$ & $1.3 \mathrm{abc}$ \\
2 & 0 & 5.0 & & $7.0 \mathrm{c}$ & $1.3 \mathrm{abc}$ \\
1 & 0 & .2 .5 & & $6.7 \mathrm{c}$ & $1.3 \mathrm{abc}$ \\
3 & 0 & 10.0 & & $5.5 \mathrm{c}$ & $1.4 \mathrm{abc}$ \\
DMS & & & & 10.44 & 0.44
\end{tabular}

Medias con letras iguales en la misma columna, no presentan diferencias significativas (Tukey, 0.05). DMS $=$ Diferencia mínima significativa.

Un aspecto poco considerado durante la etapa de proliferación es el contenido de agua en los tejidos, a pesar de que está asociado con la hiperhidratación (Channuntapitat et al., 2003; Rogalski et al., 2003). En la Figura 1 se muestra que el contenido de agua en los tejidos varió de 79.0 a $87.7 \%$. En los tratamientos $\sin \mathrm{NH}_{4} \mathrm{NO}_{3}$ $(1,2$ y 3$)$ los contenidos de agua fueron inferiores $\mathrm{y}$ diferentes $(\mathrm{P} \leq 0.05)$ a los tratamientos 12 y 9 que contenían 4 y $8 \mathrm{mM}$ de $\mathrm{NH}_{4} \mathrm{NO}_{3}$ respectivamente, más 10 $\mu \mathrm{M}$ de BA. En estas condiciones (Tratamientos 8, 9, 10, 11 y 12) los explantes mostraron síntomas de hiperhidratación, por lo que es necesario reducir la cantidad de esta sal en el medio y así evitar la hiperhidratación como la observada en chabacano cvs. 'Currot' y 'Helena' (Pérez-Tornero y Burgos, 2000) y en almendro cv. 'Nonpareil', cultivados en medios de cultivo con $10 \mu \mathrm{M}$ de BA (Channuntapipat et al., 2003).

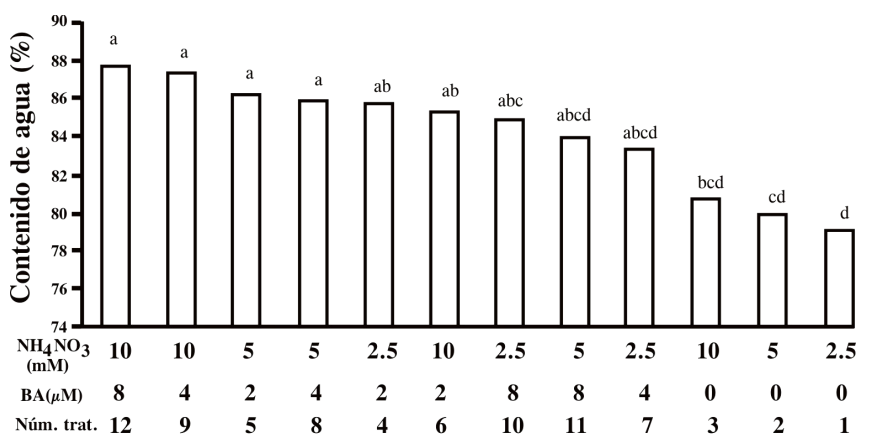

Figura 1. Efecto de la concentración de $\mathrm{NH}_{4} \mathrm{NO}_{3}$ y $\mathrm{BA}$ en el contenido de agua en brotes del híbrido almendro $x$ durazno $\mathrm{H1}$ desarrollados in vitro. DMS = 5.1. 


\section{Enraizamiento in vitro}

Las concentraciones de AIB tuvieron efecto en el número de raíces producidas por brote $(\mathrm{P} \leq 0.05)$, ya que con 2.1 y $3.4 \mu \mathrm{M}$ de esta auxina se maximizó esta variable, mientras que en ausencia de auxina no hubo enraizamiento (Cuadro 6). Para longitud de raíces, con el tratamiento $0.1 \mu \mathrm{M}$ de AIB se logró el mayor tamaño $(\mathrm{P} \leq 0.05)$ que con $3.4 \mu \mathrm{M}$ que dio el menor tamaño. Se encontró que a mayor concentración de AIB, se aumentó el número de raíces pero disminuyó la longitud de éstas, lo que demuestra el efecto inhibidor de las auxinas en la elongación de raíces; esto podría explicar la dificultad que presentan las especies de Prunus para enraizar in vitro, y que ha obligado a los investigadores a colocar los explantes por 3 ó $5 \mathrm{~d}$ en medio para enraizamiento para luego transferirlos a medio sin auxinas (Espinosa et al., 2006; Channuntapipat et al., 2003). En el presente trabajo el enraizamiento se llevó a cabo sin cambiar de medio a los explantes.

Cuadro 6. Efecto de la concentración de la auxina AIB en la longitud y número de raíces, durante el enraizamiento in vitro del híbrido almendro $\mathrm{x}$ durazno $\mathrm{H1}$.

\begin{tabular}{cccccc}
\hline Variables & \multicolumn{4}{c}{$\operatorname{AIB}(\mu \mathrm{M})$} & \\
\cline { 2 - 5 } & 0 & 0.1 & 2.1 & 3.4 & DMS \\
\hline Longitud de raíces (cm) & $0.0 \mathrm{c}$ & $0.9 \mathrm{a}$ & $0.9 \mathrm{ab}$ & $0.5 \mathrm{~b}$ & 0.46 \\
Número de raíces & $0.0 \mathrm{~b}$ & $0.5 \mathrm{~b}$ & $1.4 \mathrm{a}$ & $1.7 \mathrm{a}$ & 0.52
\end{tabular}

Medias con letras iguales en la misma hilera, no presentan diferencias significativas (Tukey, 0.05). DMS $=$ Diferencia mínima significativa.

A los brotes que no produjeron raíces (p. e., en el testigo), al ser trasplantados a suelo se les aplicó Radix $10000 \circledast$ a $20 \%(\mathrm{p} / \mathrm{p})$ y así también se logró el enraizamiento; es decir, es posible evitar la fase de enraizamiento in vitro toda vez que también puede lograrse ex vitro.

\section{Aclimatación}

La sobrevivencia de plantas en esta fase se analizó con base en los tratamientos de auxinas que recibieron durante el enraizamiento in vitro. El mayor porcentaje de plantas aclimatadas en la primera fecha fue de $45 \%$, en el tratamiento con $0.1 \mu \mathrm{M}$ de auxina y en el testigo al que se aplicó Radix $10000 \circledast$ a $20 \%(\mathrm{p} / \mathrm{p})$ al momento del trasplante debido a que no tenían raíces (Figura 2). El hecho de que los explantes sin raíces hayan sobrevivido, implica que tenían primordios de raíz o que el tratamiento con Radix® estimuló el enraizamiento lo que confirma que en el híbrido $\mathrm{H} 1$ la formación de raíces puede hacerse directamente en suelo y así ahorrar tiempo y dinero, como se ha observado en otras especies (Hartmann et al., 2002).
En el segundo experimento, nuevamente los brotes del testigo y los tratados con $0.1 \mu \mathrm{M}$ de auxina fueron los que presentaron mayor aclimatación con $60 \%$ (Figura 2); estos resultados son considerados aceptables, de acuerdo con lo indicado por Espinosa et al. (2006), y muestran que el protocolo aquí utilizado es apropiado para la micropropagación del híbrido H1. La mayor sobrevivencia en la segunda fecha (Figura 2), se atribuye a la disminución del periodo al que fueron sometidos los brotes a los tratamientos con auxina (tres semanas), ya que en la primera fecha que se cultivo por cuatro semanas hubo formación de callo que limitó el desarrollo de raíces, y comprueba que los explantes no requieren de $28 \mathrm{~d}$ para ser trasplantados. El tiempo de permanencia en el medio para enraizamiento está en función del tamaño de raíz, el cual depende a la vez de la concentración de auxina empleada en el medio y de la especie. Esto podría explicar el porqué algunos investigadores (Espinosa et al., 2006; Channuntapipat et al., 2003) utilizan dos medios de cultivo para enraizar Prunus.

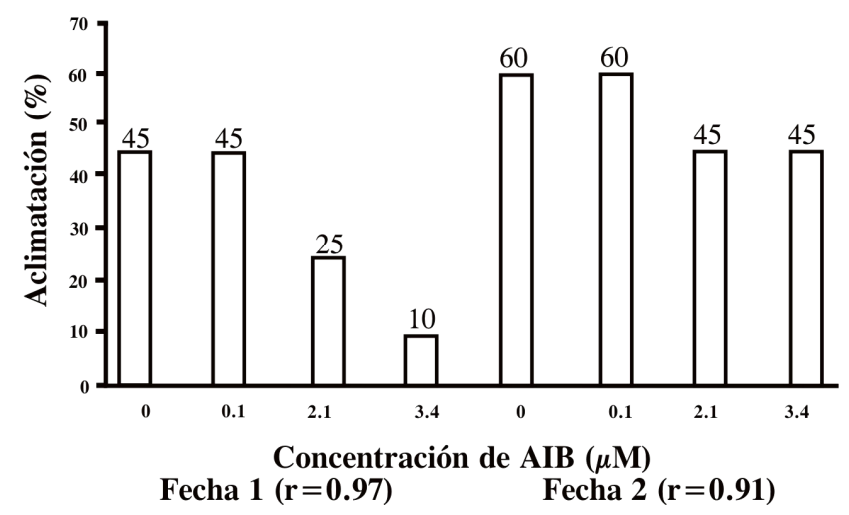

Figura 2. Porcentaje de aclimatación en plantas propagadas in vitro del híbrido almendro $\mathrm{x}$ durazno $\mathrm{H1}$, en dos fechas $\mathrm{y}$ cuatro concentraciones de AIB.

Con el fin de conocer la relación que existe entre los tratamientos empleados durante el enraizamiento y el porcentaje de aclimatación, se determinó la correlación entre ambas respuestas. En las dos fechas los coeficientes fueron altos y negativos (Figura 2), lo que indica que a mayor concentración de auxina durante el enraizamiento, menor será el porcentaje de aclimatación. Por tanto, no conviene utilizar concentraciones de auxina mayores a 0.1 $\mu \mathrm{M}$ durante el enraizamiento del híbrido $\mathrm{H} 1$.

\section{CONCLUSIONES}

La época de establecimiento in vitro influyó en la contaminación por hongos, porcentajes de brotación, sobrevivencia y muerte de explantes. El establecimiento 
óptimo ocurrió con explantes obtenidos al inicio de la brotación (22 de marzo).

Para la multiplicación de brotes, el medio de cultivo WPM adicionado con $2 \mathrm{mM}$ de $\mathrm{NH}_{4} \mathrm{NO}_{3}$ más $2.5 \mu \mathrm{M}$ de BA, produjo el máximo número de brotes (20.4), los brotes más largos $(13.7 \mathrm{~mm})$ y sin problemas de hiperhidratación, por lo que fue el mejor medio para esta fase.

La auxina AIB indujo el enraizamiento in vitro al incrementar el número de raíces, pero disminuyó la longitud de las mismas. El enraizamiento directo en suelo también es viable si los de explantes son tratados con Radix $10000 \circledast$ a $20 \%$ (p/p) al momento del trasplante.

El protocolo aquí generado permite la micropropagación del híbrido almendro $\mathrm{X}$ durazno $\mathrm{H} 1$ a partir de explantes obtenidos de plantas adultas desarrolladas en campo.

\section{BIBLIOGRAFÍA}

Channuntapipat C, M Sedgley, G Collins (2003) Micropropagation of almond cultivars Nonpareil and Plus Ultra and hybrid rootstock Titan x Nemaguard. Sci. Hort. 98:473-484.

Couto M, R Ucker, R Pedroso de Olveira (2004) Establecimento in vitro de porta-enxertos de Prunus sp. Rev. Bras. Frutic. 26:561563.

Da Silva D A, M Rogalski, L K Antunes, C Felisbino, L Crestani, M P Guerra (2003) Estabelecimento e multiplicação in vitro de porta-enxertos de Prunus. Rev. Bras. Frutic. 25:297-300.

Deogratias J M, A Lutz, F Dosba (1986) In vitro micropropagation of shoot tips from juvenile and adult Prunus avium L. and Prunus persica (L.) Batsch to produce virus free plants. Acta Hort. 193:139-144.

Enríquez J A (2001) Rescate de germoplasma de durazno Prunus persica L. Batsch., establecido en Zacatecas. In: Memoria 5 a Jornada de Investigación. Universidad Autónoma de Zacatecas. pp:23-28.

Espinosa A, P M Pijut, CH H Michler (2006) Adventitious shoot regeneration and rooting of Prunus serotina in vitro cultures. HortScience 41:193-201.

Fotopoulos S, T E Sotiropoulos (2004) In vitro propagation of the PR 2004/84 peach rootstock (Prunus persica x P. amygdalus): the effect of BAP, NAA, and $\mathrm{GA}_{3}$ on shoot proliferation. Adv. Hort. Sci. 18:101-104.

George E F (1993) Plant Propagation by Tissue Culture, Part 1. 2nd ed. Exegetics Ltd. Somerton. UK. $345 \mathrm{p}$.

Hammerschlag F (1982) Factors affecting establishment and growth of peach shoots in vitro. HortScience 17:85-86.

Hartmann H T, D E Kester, F T Davies Jr, R L Geneve (2002) Plant Propagation. Principles and Practices. Prentice Hall. Upper Saddle River, New Jersey. 645 p.
Kamali K, E Majidi, R Zarghami (2001) Micropropagation of GF-677 rootstocks (Prunus amygdalus x $P$. persica). Seed and Plant 17:175-177.

Lloyd G, B McCown (1980) Commercially feasible micropropagation of mountain laurel Kalmia latifolia, by use of shoot-tip culture. Int. Plant Prop. Soc. Comb. Proc. 30:421-427.

Marin J A (2003) High survival rates during acclimatization of micropropagated fruit tree rootstocks by increasing exposures to low relative humidity. Acta Hort. 616:139-142.

Murashige T, F Skoog (1962) A revised medium for rapid growth and bioassays with tobacco tissue cultures. Physiol. Plant. 15:473497.

Perez-Tornero O, L Burgos (2000) Different media requirements for micropropagation of apricot cultivars. Plant Cell Tiss. Org. Cult. 63:133-141.

Posser S C A, J C Fachinello, G R L Fortes, I Citadin, A C Rodriguez, A C Quezada, J B Silva (2001) Multiplicação in vitro de porta-enxertos do genero Prunus sob diferentes concentrações de BAP en dois meios de cultura. Rev. Bras. Frutic. 23:488-492.

Rodrigues C, C A Posser, G R De Luces, J C Fachinello, J Baptista (2003) Estabelecimento e multiplicação in vitro de Prunus sp. em diferentes meios de cultivo. Rev. Bras. Frutic. 25:131-133.

Rogalski M, L K Antunes, C Felisbino, L Crestani, M P Guerra, A Lima (2003) Aclimatização de porta-enxertos de Prunus $s p$. micropropagados. Rev. Bras. Frutic. 25:279-281.

Ruzic D, M Saric, R Cerovic, L Culatif (2000) Relationship between the concentration of macroelements, their uptake and multiplication of cherry rootstock Gisela 5 in vitro. Plant Cell Tiss. Org. Cult. 63:9-14.

Salazar D M, P Melgarejo (2002) El Cultivo del Almendro. Ed. MundiPrensa. Madrid. $234 \mathrm{p}$.

Tabachnik L, D E Kester (1977) Shoot culture for almond and almond peach hybrid clones in vitro. HortScience 12:545-547.

Theiler-Hedtrich C M, W Feucht (1985) Micropropagation of Prunus cerasus rootstocks - Influence of culture medium constituents on growth in stage I and II. Acta Hort. 169:335-340.

Tsipouridis C, T Thomidis (2003) Methods to improve the in vitro culture of GF677 (peach x almond) peach rootstock. New Zealand J. Crop Hort. Sci. 31:361-364.

Valentini G H, R E Murray, L E Arroyo (2006) Evaluación de los efectos de distintos portainjertos sobre la calidad de los frutos de dos variedades de duraznero cultivadas en el nordeste de la provincia de Buenos Aires (Argentina). RIA 35:71-89.

Vieitez A M, A Ballester, M C San-José, E Vieitez (1985) Anatomical and chemical studies of vitrified shorts of chesnut regenerated in vitro. Physiol. Plant. 65:177-184.

Villegas A (1990) Métodos asépticos. In: Fundamentos Teórico-Prácticos del Cultivo de Tejidos Vegetales. C H Rossell y V M Villalobos (ed). FAO. No.105 Roma. pp:21-27.

Villegas M A, C Mazuelos, M Cantos, A Troncoso (1992) Influencia del nitrógeno sobre el desarrollo in vitro del portainjerto de vid 161-49. Suelo y Planta 2:529-539. 